University of Nebraska - Lincoln

DigitalCommons@University of Nebraska - Lincoln

2010

\title{
Landmark use by Clark's nutcrackers (Nucifraga columbiana): Influence of disorientation and cue rotation on distance and direction estimates
}

\author{
Debbie M. Kelly \\ University of Saskatchewan, Debbie.Kelly@usask.ca \\ Alan Kamil \\ University of Nebraska - Lincoln, akamil1@unl.edu \\ Ken Cheng \\ Macquarie University, Sydney, NSW, Australia
}

Follow this and additional works at: https://digitalcommons.unl.edu/bioscibehavior

Part of the Behavior and Ethology Commons

Kelly, Debbie M.; Kamil, Alan; and Cheng, Ken, "Landmark use by Clark's nutcrackers (Nucifraga columbiana): Influence of disorientation and cue rotation on distance and direction estimates" (2010). Papers in Behavior and Biological Sciences. 48.

https://digitalcommons.unl.edu/bioscibehavior/48

This Article is brought to you for free and open access by the Papers in the Biological Sciences at DigitalCommons@University of Nebraska - Lincoln. It has been accepted for inclusion in Papers in Behavior and Biological Sciences by an authorized administrator of DigitalCommons@University of Nebraska - Lincoln. 


\title{
Landmark use by Clark's nutcrackers (Nucifraga columbiana): Influence of disorientation and cue rotation on distance and direction estimates
}

\author{
Debbie M. Kelly, ${ }^{1}$ Alan C. Kamil, ${ }^{2}$ and Ken Cheng ${ }^{3}$ \\ 1. Department of Psychology, University of Saskatchewan, 9 Campus Drive, Saskatoon, SK, S7N 5A5, Canada \\ 2. University of Nebraska-Lincoln, Lincoln, NE, USA \\ 3. Macquarie University, Sydney, NSW, Australia \\ Corresponding author - Debbie M. Kelly, email debbie.kelly@usask.ca
}

\begin{abstract}
Many species have been shown to encode multiple sources of information to orient. To examine what kinds of information animals use to locate a goal we manipulated cue rotation, cue availability, and inertial orientation when the food-storing Clark's nutcracker (Nucifraga columbiana) was searching for a hidden goal in a circular arena. Three groups of birds were used, each with a different goal-landmark distance. As the distance between the goal and the landmark increased, nutcrackers were less accurate in finding the correct direction to the goal than they were at estimating the distance (Experiment 1). To further examine what cues the birds were using to calculate direction, the featural cues within the environment were rotated by $90^{\circ}$ and the birds were either oriented when searching (Experiments 2 and 3) or disoriented (Experiment 3). In Experiment 4, all distinctive visual cues were removed (both internal and external to the environment), a novel point of entry was used and the birds were either oriented or disoriented. We found that disorienting the nutcrackers so that they could not use inertial cues did not influence the birds' total search error. The birds relied heavily but not completely on cues within the environment, as rotating available cues caused them to systematically shift their search behavior. In addition, the birds also relied to some extent on Earth-based cues. These results show the flexible nature of cue use by the Clark's nutcracker. Our study shows how multiple sources of spatial information may be important for extracting multiple bearings for navigation.
\end{abstract}

Keywords: Landmark use, distance and direction estimation, intra-environmental cues, Clark's nutcracker

\section{Introduction}

Navigation is important for many animals. It allows for activities, such as the relocation of nest sites, movement between foraging patches, or for the migration to overwintering grounds. Navigation may occur over a range of distances, from a few meters (e.g., fiddler crabs, Zeil and Hemmi 2006), to tens of meters (e.g., desert ants, Müller and Wehner 1994; Wehner 2003) to thousands of kilometers (e.g., wandering albatrosses, Jouventin and Weimerskirch 1990). Navigating animals use many mechanisms and cues to navigate. Compass or directional information may be extracted from the sun and the pattern of polarized light in the sky (Wehner 2003; Wiltschko et al. 1999), the center of rotation of stars (Emlen 1970), the earth's magnetic field (Lohmann et al. 2008; Wiltschko and Wiltschko 2004), odor cues (Lohmann et al. 2008; Nevitt 2008; Wallraff 2004), as well as global landmarks (Menzel et al. 2005; Towne and Moscrip 2008; von Frisch and Lindauer 1954). Many animals can keep track of the distance and direction that they have traveled from a starting point, a process called path integration (insects, Cheng et al. 2006; Wehner and Srinivasan 2003; rodents, Etienne 2003; Etienne and Jeffery 2004). Many animals can also use visual landmarks to pinpoint a target location (e.g., desert ants, Wehner and Räber 1979; honeybees, Cartwright and Collett 
1983; pigeons, Cheng 1988, 1989; dogs, Fiset 2007; squirrels, Vlasak 2006). The psychological and biological literatures provide a wealth of information as to how different species use various mechanisms, either alone or in combination, to locate or re-locate a desired position (see Gallistel 1990; Healy 1998; Jeffery 2003; Shettleworth 1998).

In the multiple bearings hypothesis, Kamil and Cheng (2001) suggested that the use of multiple cues might be necessary to obtain the high levels of accuracy required to locate food caches. Food-storing animals, for instance, may use multiple cues to increase their accuracy in finding their buried food stores. Estimating the distance between one cue and a storage site can be inaccurate, especially when the distance between the cue and the site is great. Indeed, formal modeling shows that search error is greatly reduced by using multiple landmarks (Kamil and Cheng 2001).

Clark's nutcrackers, like other species of food-storing birds, use multiple landmarks to navigate (e.g., LaDage et al. 2009). Vander Wall (1982) allowed birds to cache in a large open aviary with many objects that could be used as landmarks. On non-reinforced test trials, he displaced the landmarks in one half of the aviary by $20 \mathrm{~cm}$. Near the boundary between shifted and unshifted landmarks, the birds appeared to use both the shifted and unshifted landmarks in that they searched about halfway between the actual cache location and the location indicated by the shifted landmarks. Further support for the use of multiple landmarks by nutcrackers comes from a study in which nutcrackers were trained to find a goal that was located a constant direction and distance from a configuration of nine landmarks (Basil 1993). When tested with only a subset of the training landmarks available, the birds were accurate at locating the position of the goal area when as few as three of the original nine landmarks were available. Kamil et al. (2001) also found that Clark's nutcrackers reduced their search errors when multiple landmarks were available. Thus, it is clear that nutcrackers, and some other birds (e.g., European jays, Bennett 1993; pigeons, Cheng 1988, 1989; chicks, Della Chiesa et al. 2006), encode multiple landmarks for locating caches.

In the current study, we were primarily interested in how animals use multiple sources of spatial information to orient in a small-scale search task. We chose Clark's nutcrackers as our model species due to their strong reliance on spatial memory. During the fall an individual nutcracker will make tens of thousands of widely scattered caches. These caches become the primary source of food for the individual and its offspring in the following spring (see Balda 1987). Thus, the ability to accurately remember the location of these food caches is critical, and indeed nutcrackers have been shown to have excellent spatial memory in natural and laboratory tasks (Kamil and Balda 1985; Gould-Beierle 2000; Tomback 1980).
In the current study, we were primarily interested in how Clark's nutcrackers determine the location of a hidden food reward, in a laboratory setting, when provided with only one reliable cue, a cylindrical landmark. A single cylinder gives no directional cues itself (there are no features to identify one "side"), but a number of animals can nevertheless use it for localization in a laboratory setting: honeybees (Cartwright and Collett 1983), pigeons (Cheng 1994), gerbils (Collett et al. 1986). We largely eliminated environmental geometry as an informative cue (Cheng and Newcombe 2005) by training and testing the birds in a nearly circular 24-sided enclosure. Potential directional cues included featural cues on the wall, a large wooden beam in the middle of the enclosure, place of entrance into the arena, inertial cues, and any available unmanipulated Earth-based cues (e.g., magnetic cues).

We trained birds to find a hidden goal at different distances from the single landmark. We then used the distance at which the birds were most accurate for the rest of our manipulations: (a) cue rotation, (b) cue removal, (c) disorientation, and (d) arena entry point. These manipulations allowed us to examine which of the available cues were encoded by the birds.

\section{Materials and methods}

\section{Subjects}

Eighteen wild-caught adult Clark's nutcrackers (Nucifraga columbiana) served as subjects. Data collection began November 2002 and was completed November 2004. All birds had previous experience with unrelated experiments but were naïve to spatial search tasks in a circular arena; the birds were in captivity between 5 and 10 years. The birds were maintained at $85 \%$ of their free feeding weight with pine seeds obtained during experimental sessions and supplemental feedings consisting of turkey starter, sunflower seeds, parrot pellets, mealworms, pine seeds, and vitamin supplement. They were housed individually in large cages $(73 \mathrm{~cm}$ height $\times 48 \mathrm{~cm}$ wide $\times 48 \mathrm{~cm}$ deep) with free access to water and grit. The colony was maintained on a 14:10 light-dark cycle with lights on at $6 \mathrm{a} . \mathrm{m}$. The housing room was maintained at $22^{\circ} \mathrm{C}$.

\section{Apparatus}

The experiment was conducted in a symmetrical 24sided fully enclosed environment (4.66 $\mathrm{m}$ in diameter) designed to approximate a circular room (see Figure 1). Lighting was provided through 12 pot lights (40 watts each) arranged symmetrically on the ceiling of the arena. Each light was centered over each of the 12 openings and located $60 \mathrm{~cm}$ from the wall. Each side of the arena 


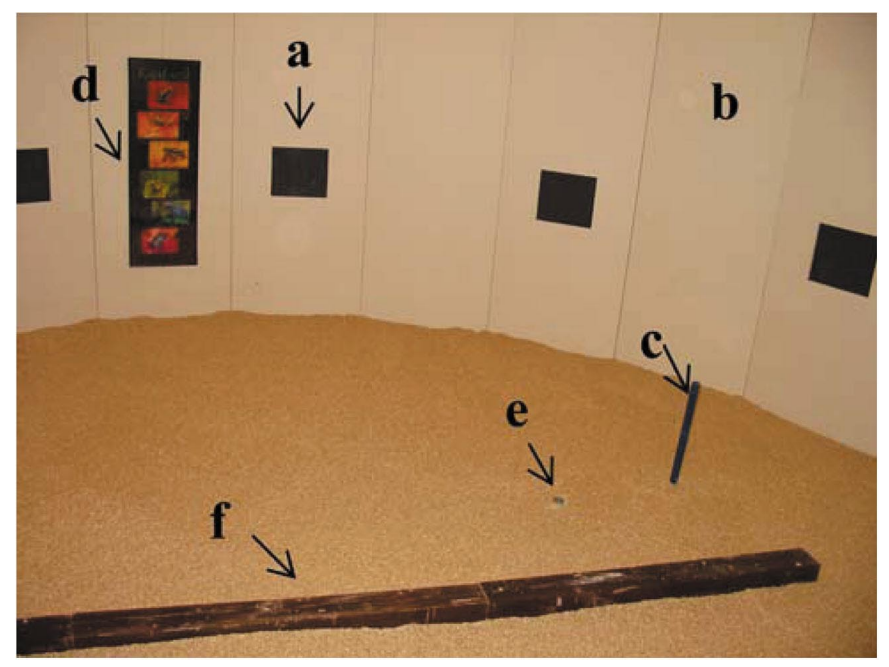

Figure 1. An illustration of experimental room. The example shows a typical trial for a bird in group 40. The distinctive features are indicated: $(a)$ a porthole used to shuttle the birds in and out of the experimental arena, $(b)$ an entrance door used by the experimenter to enter and exit the arena, (c) the single blue landmark, $(d)$ the poster of rain forest frogs (one of the two posters positioned within the arena), (e) the goal, and (f) the central wooden beam.

was $61 \mathrm{~cm} \times 244 \mathrm{~cm}$ (width and height, respectively) and to maintain symmetry the side either contained a small square central porthole $(25.5 \mathrm{~cm}$ side) located $61 \mathrm{~cm}$ from the floor, or was constructed as a large entrance door (i.e., the presence of either a porthole or an entrance alternated; see Figure 1). The porthole allowed the birds to enter and exit the experimental enclosure, whereas the experimenter could enter and exit from the larger entrance doors. Outside the experimental enclosure, a holding cage was positioned flush against a porthole. The section of the cage that was aligned with the porthole was removed thus permitting the bird to enter and exit the holding cage as required without being handled.

The experimental enclosure had a raised wooden floor $7 \mathrm{~cm}$ above the concrete floor of the outer room. A grid of squares $(10 \mathrm{~cm}$ by $10 \mathrm{~cm})$ was marked on the center wooden floor (diameter $2.3 \mathrm{~m}$ ) to allow for accurate placement of the landmark and goal. The origin of the grid was at the center of the enclosure, dividing the enclosure into four equal quadrants. Approximately 2$3 \mathrm{~cm}$ of aspen chip substrate covered the entire surface of the wooden floor.

Three main featural cues were presented in the experimental enclosure. One directional cue consisted of three sections of brown painted wooden beam (each section was $100 \mathrm{~cm} \times 9 \mathrm{~cm} \times 9 \mathrm{~cm}$ ) placed lengthwise down the center of the enclosure with each segment flush against the next. For ease of referral, these sections as a unit will be referred to as the wooden beam. The center of the wooden beam was positioned at the absolute center of the enclosure. The position of the wooden beam during training trials was stationary and perpendicular to the East and West portholes. A second directional cue consisted of two posters hung $90^{\circ}$ apart. One color film poster of Chez Panisse $(56.7 \mathrm{~cm}$ wide $\times 71.5 \mathrm{~cm}$ long) was centered on the northern-most wall segment and the second poster was a uniquely colored series of photographs of rainforest frogs $(30.2 \mathrm{~cm}$ wide $\times 91.8 \mathrm{~cm}$ long; shown in Figure 1) centered on the eastern-most wall segment. Both posters were hung such that the bottom of each poster was $30 \mathrm{~cm}$ from the wooden floor of the experimental enclosure. Finally, one cylindrical object $(40 \mathrm{~cm}$ tall with a $2.5 \mathrm{~cm}$ diameter), painted blue to make it distinctive, was provided as a landmark for exact localization. It was constructed from polyvinyl chloride (pvc) pipe and secured to a Plexiglas base, and was present in the enclosure at all times with the exception of familiarization sessions. This blue landmark was maintained in a constant relationship to the goal location.

A Panasonic WV-BL200 black and white video camera was mounted to the outside top of the experimental enclosure. A central small opening permitted only the lens of the camera to be visible from inside the enclosure. A Sony GV-D1000 NTSC mini digital videocassette recorder and a Panasonic TR-930B video monitor were connected to the video camera to allow for monitoring and recording of experimental sessions from outside of the enclosure.

\section{General procedures}

Birds were carried by hand from the colony room and placed in the holding cage. Prior to the start of each trial, the landmark (with the exception of familiarization trials in which no landmark was present) and goal were positioned according to a predetermined schedule. The position of the goal on each trial was randomly chosen from all possible goal locations without replacement (refer to the introduction of each individual Experiment for specific details regarding goal-landmark relationship). Each quadrant was used once per day. To begin each trial, the lights in the holding area, including the holding cage, were turned off while the lights in the experimental enclosure were illuminated. The sliding door covering the porthole was opened to allow the bird access to the experimental enclosure. Each trial lasted until the bird found the seeds or until 10 min elapsed, which ever occurred first. After completion of the trial, the lights in the experimental enclosure were extinguished and the light in the holding cage was illuminated. Once the bird returned to the holding cage the door to the porthole was closed securing the bird in the holding cage until the beginning of the next trial. Upon completion of each daily session the bird was returned to its individual cage in the colony room. 


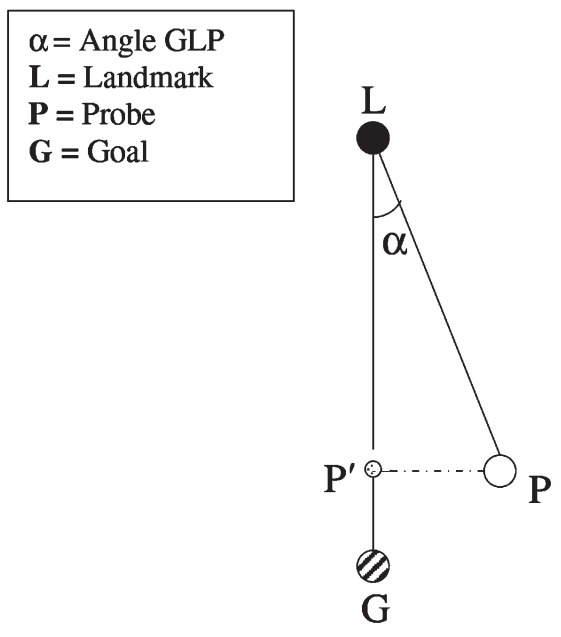

Figure 2. Schematic representation depicting calculation of measurements for direction, distance, and total errors.

To ensure the landmark was the only factor reliably predicting the position of the goal, the landmarkgoal array was presented at different locations within the experimental room across trials. However, the landmark-goal array maintained the same orientation relative to the walls and other directional references within the room (e.g., the posters and wooden beam). The landmark and goal were always located to the East or West of the wooden beam. The locations were defined by the location of the goal for each individual trial. Sixty different goal locations were used with the minimum distance between two possible goal positions being $20 \mathrm{~cm}$. Furthermore, the goal was never placed closer than $20 \mathrm{~cm}$ or further than $100 \mathrm{~cm}$ from either side of the wooden beam. The final restriction on the selection of the goal location for each trial was that it had to appear in each of the four quadrants of the grid (see "Apparatus" Section) once per day.

\section{Data recording and analysis}

Data consisted of reinforced training trials and occasional non-reinforced tests that were $5 \mathrm{~min}$ in duration. Both were videotaped and converted to digital movie files to allow for frame-by-frame playback. For every trial, a separate static bitmap was created for the landmark-goal array and the first 10 probes made by each nutcracker (as defined by the beak touching the substrate) for all buried training trials and all testing trials using Adobe Premiere (Pinnacle Systems, Braunschweig, Germany). On occasional trials birds engaged in probing behavior at the edges of the enclosure, thus the few probes that occurred outside of a $100-\mathrm{cm}$ radius around the goal location were discounted. The positions of the goal, the landmark, and the first 10 probes were plotted from the bitmaps on an $\mathrm{x}-\mathrm{y}$ axes using Sigma Scan Pro (Version 5.0, SPSS, Chicago). Error was measured as the absolute distance of the first 10 probes (per trial) from the goal location and averaged for each trial for each bird. These averages were used to calculate four values for each trial (for each bird): (a) distance error: The distance in centimeters was calculated between the landmark position and the probe position (LP in Figure 2). Then the distance in centimeters was calculated between the landmark position and the goal position (LG in Figure 2). The distance error was then determined as $|\mathrm{LP}-\mathrm{LG}|$, i.e., the absolute difference between LP and LG, (b) direction error: The distance in centimeters was calculated from $\mathrm{P}$ to $\mathrm{P}^{\prime}$, where $\mathrm{P}^{\prime}$ is the probe position projected onto the line LG, (P-P' is shown as the dashed line in Figure 2), (c) angular error: the angle GLP was calculated, and (d) total error: the Pythagorean theorem was used to calculate the total search error for each probe.

Mixed factor analyses of variance (ANOVAs) were used to analyze the data. Subsequent Fisher's Least Significant Difference Multiple Comparisons (Fisher's LSD) tests were used only after significant $F$ ratios. Initial analyses used total error to compare the testing conditions. Subsequent ANOVAs were conducted to examine error as a function of the absolute distance and direction error (error type was a factor in such ANOVAs). All significance testing was conducted at $\alpha=0.05$.

\section{Experiment 1}

Experiment 1 examined whether nutcrackers would show predictable changes in search error when estimating the distance and direction of a goal location from a single landmark, as the goal-landmark distance increased within a circular arena. Three groups of birds were trained and tested, each with a different distance between the goal location and a single landmark.

Prior to the beginning of training the nutcrackers were given five sessions, four trials per session, to familiarize them with the experimental arena. During each trial, two pine seeds with shells removed were placed on a lid from a $35-\mathrm{mm}$ film container on the surface of the substrate. The position of the lid was randomly determined for each session. The landmark was not present during these trials. Each trial lasted until the bird ate the available pine seeds or until 10 min elapsed, whichever occurred first. By the end of this stage, all birds were readily consuming the pine seeds.

All birds were then trained with the landmark directly south of the goal. The birds were randomly assigned to one of three groups. For group 40, the landmark and goal were separated by $40 \mathrm{~cm}$. For group 90, the landmark-goal distance was $90 \mathrm{~cm}$. Finally, for group 140, the landmark-goal distance was $140 \mathrm{~cm}$. The landmark-goal distances were chosen to be within the range of training distances used in previous experiments (Goodyear and Kamil 2004). 
The nutcrackers were trained to accurately locate the position of the hidden goal in four stages. During the first stage of training, the initial three trials of the day were conducted with the goal visible on the substrate surface. Only the final trial was conducted with the seeds completely buried and thus requiring the birds to remove the substrate to find the seeds. This stage lasted 5 sessions. During the second stage, the target was showing on only the first two trials; the last two trials had the seeds completely buried. This training stage lasted 10 sessions. During the third stage, only the first trial had the target showing; the remaining three trials had the seeds completely buried. This stage lasted 15 sessions. In the fourth stage of training, the seeds were completely buried on all trials. This stage lasted 5 sessions. Upon completion of the fourth training stage the birds were given 30 sessions in which one trial per day was a non-reinforced probe trial. These probe trials were conducted to measure search accuracy in the absence of any possible food-related cues. The probe trial was randomly presented within the session with the exception that it could never occur on the first trial of the session. Because no goal was present on probe trials, they were ended after $5 \mathrm{~min}$ had elapsed or the bird made 10 probes, by turning out the lights in the arena and opening the West porthole between the test room and the holding cage.

Given the significant amount of time necessary to conduct each experimental session, the birds were randomly divided into two squads with the restriction that each squad included three birds from each of the three groups. The two squads received the same familiarization, training, and testing procedures. The second squad started immediately upon completion of all training and testing procedures by the first squad. One bird, from group 140, failed to search when the two seeds were fully buried (i.e., the fourth training stage) and was dropped from the study.

\section{Experiment 2}

In the rest of the experiments, only the six nutcrackers from group 40 participated. Group 40 was chosen as the only group to participate in this experiment due to the consistent and reliable search accuracy shown by this group.

In Experiment 2, we examined whether the intra-environmental cues were controlling the birds' search behavior by systematically rotating the posters, the bird's entrance into the experimental environment, and the wooden beam by $90^{\circ}$. If the intra-environmental cues were the only cues that controlled search, we would expect that the birds would shift their focus of search by $90^{\circ}$, from the northernmost quadrant to the easternmost quadrant.
Birds were given two familiarization sessions prior to training. The birds then started at the second stage of training, with the target showing on only the first two trials, and the seeds completely buried on the last two trials. This training stage lasted 5 sessions. The birds subsequently received 5 sessions of the third and fourth training stages. Finally, the birds received 10 sessions of the final training stage (i.e., one non-reinforced trial per session) before moving on to testing.

Testing immediately followed completion of training. Each daily session consisted of four trials: 3 reinforced baseline trials and 1 non-reinforced trial. This non-reinforced trial was either a $0^{\circ}$ rotation test or a $90^{\circ}$ rotation test trial. Both types of trials were always non-reinforced and thus were ended by turning out the lights in the enclosure, after a minimum of 10 probes were made or $5 \mathrm{~min}$ had elapsed, whichever occurred first.

Testing was conducted in two blocks with 10 testing sessions per block. Four of these sessions contained one $90^{\circ}$ rotation test trial and six of these sessions contained one $0^{\circ}$ rotation test trial, resulting in a total of eight $90^{\circ}$ rotation tests and $120^{\circ}$ rotation tests. The order of session presentation was randomized with the constraint that two sessions containing $90^{\circ}$ test trials could never occur consecutively. During each block, the position of the goal was randomly selected such that it occurred in each of the four quadrants once per session. Each block was separated by 5 sessions without test trials (i.e., 3 reinforced baseline trials and 1 non-reinforced trial per session).

The $0^{\circ}$ rotation test trials were procedurally identical to the non-reinforced trials of the last training stage. During the $90^{\circ}$ rotation test trials, however, the wooden beam and the two posters were rotated by $90^{\circ}$ in a clockwise direction from their original position (see Figure 3 for a schematic representation. Note that due to its cylindrical nature of the blue landmark it is unaffected by rotation). In addition, the birds entered from a porthole $90^{\circ}$ clockwise from the porthole used on $0^{\circ}$ rotation test trials. Thus, entrance direction, posters, and wooden beam were all rotated by the same amount.

\section{Experiment 3}

Experiment 3 repeated the tests of Experiment 2, but inertial cues were eliminated by disorienting the birds. At the beginning of each trial, the bird was placed in the holding cage which was now encased in an opaque cover to eliminate extra-environmental visual cues. The cage was moved to one of four "disorientation stations" (counterbalanced for order) outside of the experimental arena. At this location, the bird was disoriented by slowly turning the cage on a swiveling chair at approximately 10-12 rpm for $1 \mathrm{~min}$ (this procedure has been used successfully to induce disorientation; for examples 


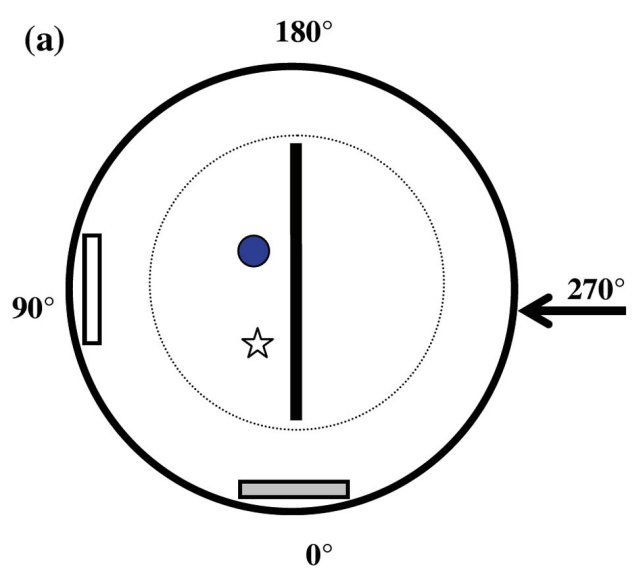

$\mathbf{N}$

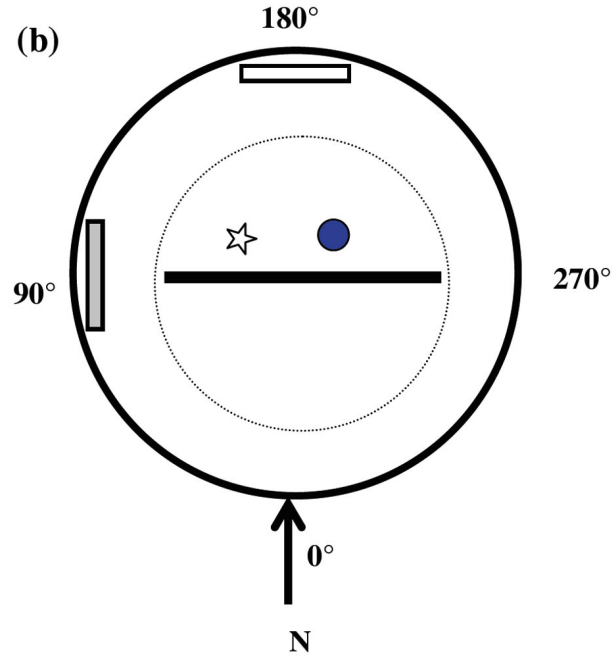

Figure 3. Schematic representation of one possible arrangement of the goal-landmark array within the experimental enclosure (the goal-landmark array was presented in a different location on each trial). The outermost open circle depicts the 24-sided circular enclosure. The innermost dashed circle represents the range of possible goal locations. The two smaller rectangles represent the position of the two posters (the open and filled pattern illustrates that the two posters were visually distinct), the thick line in the center represents the wooden beam, the filled circle represents the blue landmark and the star indicates the goal position. a) An example of the cue arrangement during $0^{\circ}$ rotation trials. b) The same cue arrangement example during a $90^{\circ}$ rotation trial. With the exception of the relationship between the overall arena size and the area of possible goal locations, the diagram is not drawn to scale.

see Margules and Gallistel 1998; Kelly and Spetch 2001; Kelly et al. 1998; Vallortigara et al. 1990 for use in different species). The covered cage was then moved, by means of a random walking pattern, from the disorientation station to the appropriate entrance porthole.

The birds received 10 sessions of the final training stage before moving on to testing, which immediately followed completion of training. The featural cues inside the enclosure and/or extra-environmental cues were manipulated in a $2 \times 2$ design. As in Experiment 2, the intra-environmental cues (i.e., the two posters and the wooden beam) were presented with a $0^{\circ}$ rotation and the same entrances used by the bird and the experimenter on training trials were used, or all intra-environmental cues and both the bird and experimenter entrances were rotated by $90^{\circ}$. In addition, in this experiment the birds were either oriented or disoriented using the disorientation procedure described above, prior to being released into the experimental enclosure. To keep the bird's experience similar on oriented and disoriented trials, the same steps were followed for the oriented trials, including placement in the rotation chamber, but the bird was not rotated.

Because the disorientation treatment might have affected behavior on subsequent trials, all test sessions, including the oriented trials, consisted of a single nonreinforced testing trial. Testing was conducted in four blocks, with each block containing two $90^{\circ}$ rotation testing sessions (one session with the bird oriented and one with the bird disoriented) and two $0^{\circ}$ rotation testing sessions (one session with the bird oriented and one with the bird disoriented); this resulted in a total of 16 testing sessions. In each block the goal position on test trials occurred once in each of the four quadrants (each test type occurred twice in each quadrant upon the completion of testing). Each testing session was separated by four sessions (one session per day) consisting of four trials (3 reinforced baseline trials and 1 non-reinforced trial) to ensure continued search performance.

\section{Experiment 4}

Experiment 4 examined the birds' search accuracy when they were required to enter the apparatus from two completely novel entrance portholes (i.e., a North-East porthole and a South-West porthole) and were either oriented or disoriented. In addition, we examined the birds' searching accuracy when all the distinctive featural cues were removed from inside, as well as outside, the environment to provide us with an overall measurement of the birds' search error when they could only use Earth-based cues.

The birds received 5 sessions of the final training stage before moving on to testing, which immediately followed completion of training. During the testing sessions all the cues in the experimental enclosure were removed and the birds were held in an opaque holding cage to remove use of external cues. The birds were either oriented or disoriented and entered the enclosure from one of two novel portholes, either the North-East 

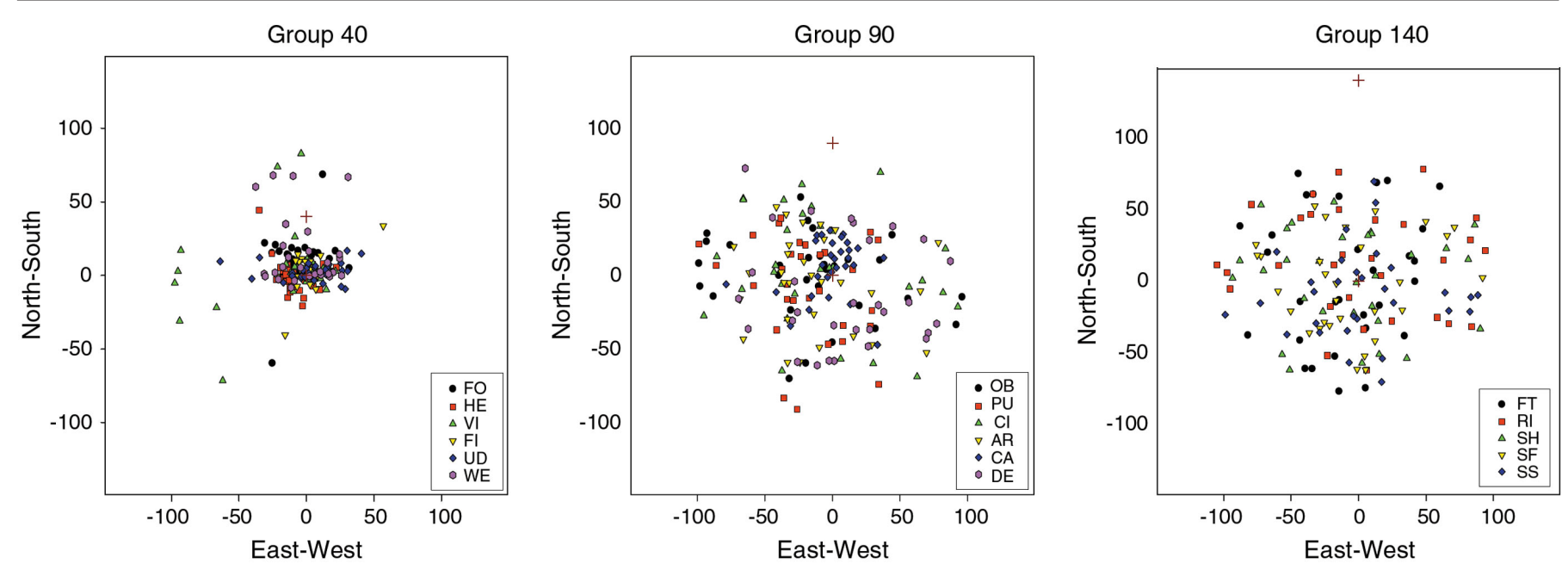

Figure 4. Location of average search position for each bird in each of the three groups used in Experiment 1: left group 40, middle group 90, and right group 140. Each symbol depicts the average of the first 10 search probes made by each bird on each training trial for the last two training blocks (15 trials per block). The uppermost cross indicates the position of the landmark and the central cross (at coordinate 0,0 ) indicates the goal location.

or the South-West porthole. Testing was conducted in two blocks, with each block containing two North-East entrance sessions (one with the birds oriented and one with the birds disoriented) and one South-West entrance sessions (one with the birds oriented and one with the birds disoriented); this resulted in a total of 8 testing sessions. In each block the goal position on test trials occurred once in each of the four quadrants (each test type occurred twice in each quadrant upon the completion of testing).

\section{Results}

\section{Experiment 1}

In Experiment 1, three groups of birds searched for targets at 40,90 , or $140 \mathrm{~cm}$ from a single landmark. The birds in group 40 quickly learned the task, whereas the other two groups performed poorly (Figure 4). To examine group differences in the acquisition of the task we compared the first five buried seed trials. The birds in group 40 learned the task more quickly than groups 90 or 140, based on a mixed ANOVA with Group (40, 90, and 140) and Trial (1-5) as factors. The main effect of group was significant $\left(F_{2,14}=6.21, p=0.012\right)$, whereas there was no significant main effect of trial $\left(F_{4,56}=1.04, p=0.39\right)$, and no interaction of group and trial $\left(F_{8,56}=2.04, p=0.058\right)$. Also, the birds in group 40 had errors of significantly smaller magnitude than groups 90 or 140, which were not significantly different from each other (Fisher's LSD test, $M s=51.15,85.23$, and $80.28 \mathrm{~cm}$, respectively).

Task acquisition was further analyzed by divid- ing the initial training trials into six 15-trial blocks (Figure 5). As acquisition proceeded the birds showed less total error, with the highest magnitude of error occurring on the first block of trials and systematically decreasing. Based on a mixed ANOVA with group (40, 90, and 140) and blocks (1-6) as factors, the main effect of group and block was significant $\left(F_{2,14}=32.78, p<0.0001\right.$ and $F_{5,70}=3.72, p=0.005$, respectively). The interaction of group by block was not significant $\left(F_{10,70}=0.50\right.$, $p=0.89$ ). Again, the birds in group 40 had a significantly smaller magnitude of error than either groups 90 or 140, which were not significantly different from each other (Fisher's LSD test, Ms $=31.0,62.2$, and $73.95 \mathrm{~cm}$, respectively; see Figure 5). The first block had larger errors than the other blocks (Fisher's LSD test, Ms $=62.37$, $54.76,57.42,52.74,52.29$, and $54.74 \mathrm{~cm}$ ).

To examine possible differences in search accuracy in distance and direction, we examined the birds' performance during the last two 15-trial blocks of training (Figure 6). We also examined whether seed availability influenced performance [Mixed ANOVA with group (40, 90, and 140), error type (distance and direction), and seed availability (present and absent) as factors]. The birds showed similar performance whether seeds were present or absent $\left(F_{1,14}=1.69, p=0.21\right)$. The birds in group 40 had errors of a smaller magnitude than groups 90 or 140, which were not significantly different from each other $\left(F_{2,14}=29.27, p<0.0001 ; M s=13.97\right.$, 36.61 , and $41.45 \mathrm{~cm}$, respectively). The birds were better at estimating distance than direction when error was calculated in centimeters $\left(F_{1,14}=22.6, p=0.0003\right)$, but when directional error was calculated in degrees (i.e., angular error) the three groups showed similar performance $\left(F_{2,14}=1.40, p>0.28\right)$. 


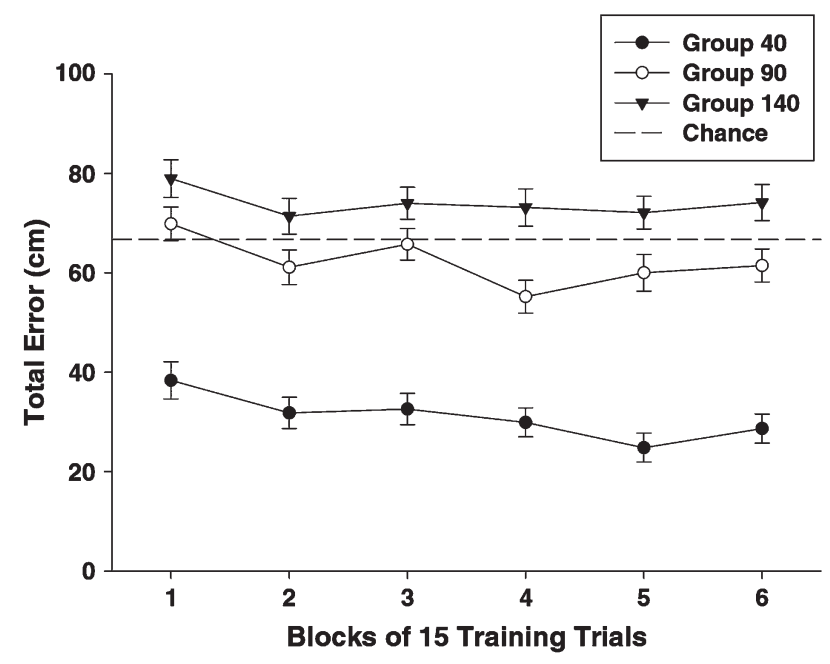

Figure 5. Acquisition (total) error for the birds in Experiment 1, shown over six blocks of training. Each block represents 15 training trials. Chance performance was calculated as $66.7 \mathrm{~cm}$, derived from the following calculation: $\left[\int_{r=0}^{1} r \times 2 \pi r\right] / \pi \times 100$ $\mathrm{cm}$ (radius within which searches were examined).

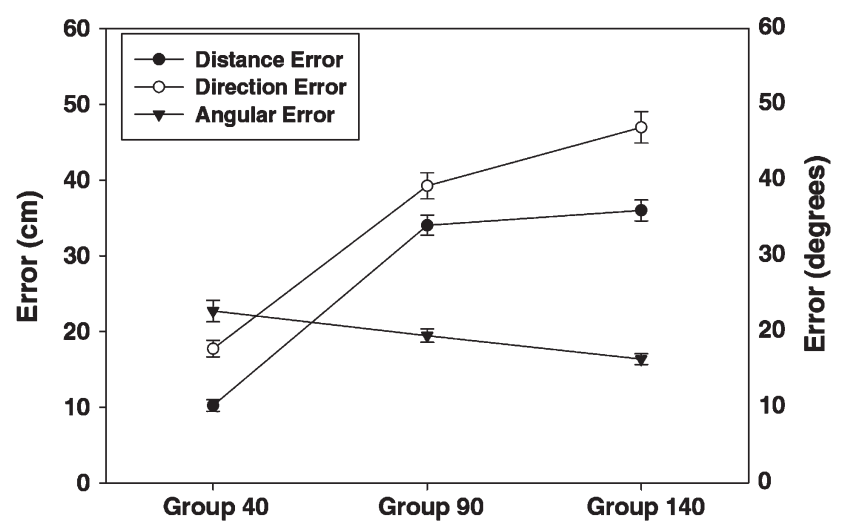

Figure 6. Average acquisition error for each group of birds in Experiment 1, showing distance, direction, and angular errors.

\section{Experiment 2}

In Experiment 2, the directional landmarks in the arena (wooden beam and posters) were rotated by either $0^{\circ}$ or $90^{\circ}$ on tests. Figure 7 shows each bird's average search location on tests. Most searching was concentrated near the target on $0^{\circ}$ tests (Figure 7, left panel), but substantial scatter was found on $90^{\circ}$ tests, sweeping an arc from the 90 quadrant through the 0 quadrant to 270 quadrant (Figure 7, right panel). Averaging across all tests for each bird, total search error was significantly greater on the $90^{\circ}$ tests than on the $0^{\circ}$ tests $(M=59.8,28.5 \mathrm{~cm}$, respectively; paired $t$ test $\left.t_{5}=-6.82, p=0.01\right)$. Rotating the featural information within the environment (i.e., the posters, the wooden beam and/or the birds' point of entrance) clearly influenced searching.
The birds searched differently in the conditions, with the birds searching at a similar distance from the landmark but not in a similar direction (Figure 7). In the $0^{\circ}$ condition, most searches concentrated at the 0 quadrant, whereas in the $90^{\circ}$ condition, searches were mostly split between the 90 and 270 quadrants. Averaging across all tests for each bird, the mean distance and direction errors are: $0^{\circ}$-distance error, $10.9 \mathrm{~cm} ; 0^{\circ}$-direction error, $10.5 \mathrm{~cm}$; $90^{\circ}$-distance error, $14.7 \mathrm{~cm}$; $90^{\circ}$-direction error, $40.7 \mathrm{~cm}$. A Fisher's LSD test showed that the $90^{\circ}$-direction error significantly exceeded the other three errors, which did not differ among themselves.

To examine, where the birds were directing their searches, we examined the spatial distribution of the birds' searches in the environment. First, for analyses purpose we divided the enclosure into four equal quadrants centered on the position of the landmark (see light gray lines in Figure 7): the 0 quadrant (the Northernmost area), the 90 quadrant (the Easternmost area), the 180 quadrant (the Southernmost area), and the 270 quadrant (the Westernmost area). We then calculated the proportion of searches made by each bird within each quadrant (a search was defined as the average spatial location of the first 10 probes made by each bird per trial). This allowed us to define a "goal" quadrant and a "rotational" quadrant. For example, during the $0^{\circ}$ tests the goal quadrant was 0 and the rotational quadrant was 180 . During the $90^{\circ}$ tests the goal quadrant was 90 and the rotational quadrant was 270 . The comparison of search distribution within these two quadrants allowed us to examine how the birds were influenced by the rotation of the cues. If the birds searched within the goal quadrant during the $0^{\circ}$ and $90^{\circ}$ tests, this would show that they were following the intra-environmental cues to determine direction. If the birds searched significantly at the rotational quadrant, this indicates a rotational error, and $180^{\circ}$ ambiguity in determining direction. The directional cue that possesses this ambiguity was the wooden beam; searching at the rotational quadrant thus implicates the use of the wooden beam in determining direction.

The birds searched more in the goal and rotational quadrants when the intra-environmental cues were not rotated $\left[2 \times 2\right.$ ANOVA with factors, condition $\left(0^{\circ}\right.$ rotation and $90^{\circ}$ rotation) and quadrant (goal and rotational), $M \mathrm{~s}=0.49$ and $0.30 \mathrm{~cm}$, respectively; $F_{1,5}=23.57$, $p=0.0047]$. Overall, searching was primarily concentrated within the goal quadrant compared to the rotational quadrant $(M s=0.56$ and 0.22 , respectively; $F$ $1,5=14.04, p=0.013)$. The greatest proportion of searching occurred in the goal quadrant during the $0^{\circ}$ condition $(M=0.89)$ which was significantly different from the proportion of searches during all other conditions $(M s=0.35,0.25$, and 0.10 for 90 rotational quadrant, 90 goal quadrant and 0 rotational quadrant). Searching was distributed equally between the goal and rotational 

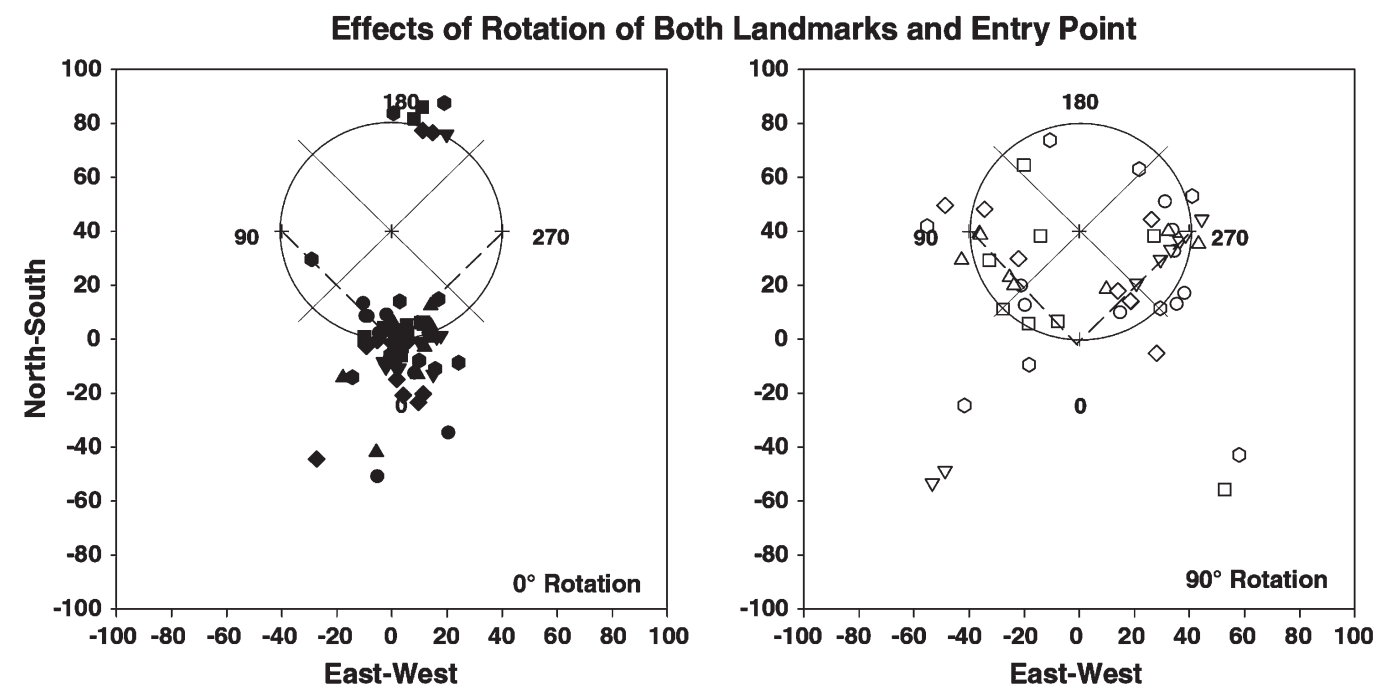

Figure 7. Left panel shows average search location for each bird during the $0^{\circ}$ rotation, and the right panel shows average search location for each bird during the $90^{\circ}$ rotation condition of Experiment 2. The central cross indicates the landmark location and the three crosses on the perimeter of the circle indicate the three possible goal locations. Each symbol shows the search location for each of the four test trials, with each different symbol representing a different bird. The numbers outside of the plot indicate search quadrant (i.e., 0, 90, 180, and 270 quadrants).

quadrant during the $90^{\circ}$ rotation condition. If the birds were using only the features within the environment we would not expect a difference between the $0^{\circ}$ rotation and $90^{\circ}$ rotation tests, as the birds should have followed the shifted features and searched in the goal location during the $90^{\circ}$ rotation test; this clearly was not the case. However, although the birds did not show complete control by the intra-environmental features, these features were still influencing the birds' search.

Finally, if the birds were using extra-environmental visual cues or Earth-based cues (e.g., magnetic compass) we would expect to see searches directed to the "absolute compass" goal quadrant (i.e., the 0 quadrant) during the $90^{\circ}$ rotation tests. We compared searches made to this absolute compass goal quadrant during the $90^{\circ}$ rotation tests to the rotationally equivalent quadrants during the $0^{\circ}$ rotation tests (the average proportion of choices to the 90 and 270 quadrants). The birds made significantly more choices to the absolute compass quadrant during $90^{\circ}$ rotational test sessions than to the rotationally equivalent quadrants during the $0^{\circ}$ rotational test sessions $(M s=0.29$ and 0.01 , respectively; paired $t$ $\left.{ }_{5}=-3.4, p=0.02\right)$. This suggests that the birds' search was significantly guided by extra-environmental visual cues or Earth-based cues during the rotational trials.

In summary, these results show that the birds were not simply responding randomly during the $90^{\circ}$ rotation trials. The majority of birds showed a bimodal search distribution, searching primarily in the 90 and 270 quadrants when the intra-environmental cues were rotated by $90^{\circ}$. This suggests that the birds were relying primarily on the wooden beam, the only directional cue that was ambiguous. The place of entrance and the post- ers provided unambiguous directional cues. However, the birds did not limit their searching to only these two rotationally correct quadrants during the $90^{\circ}$ rotational trials but also searched at a location midway between the goal location defined by the cues within the apparatus (posters and entrance) and the 0 quadrant, suggesting the use of some unidentified unshifted directional cues. These could be some Earth-based directional cues. But given that the birds in this experiment were carried to the enclosure by hand and placed in a wire mesh cage between trials, they could also have maintained a sense of direction during transport to the experimental enclosure (and while outside the experimental arena) and used this inertial directional information when searching for the goal on the $90^{\circ}$ rotation trials. In the next experiment, we examined this possibility.

\section{Experiment 3}

Experiment 3 replicated the tests of Experiment 2 with an additional factor: the birds were disoriented on half the tests. The results (Figure 8) replicated those of Experiment 2, with disorientation having little effect. The birds showed less total error on the $0^{\circ}$ tests than on the $90^{\circ}$ tests $\left(M \mathrm{~s}=26.1\right.$ and $50.8 \mathrm{~cm}$, respectively; $F_{1,15}=45.25$, $p=0.001)$, but whether or not the birds were oriented did not significantly influence performance $(M s=35.4$ and $41.6 \mathrm{~cm}$, respectively; $F_{1,15}=1.13, p=0.34$ ). The interaction of rotation and orientation was also not significant $\left(F_{3,15}=2.18, p=0.2\right)$.

Similar to Experiment 2, directional scatter increased on $90^{\circ}$ tests. Averaging across all tests for each bird, the mean distance and direction errors are: $0^{\circ}$-distance er- 

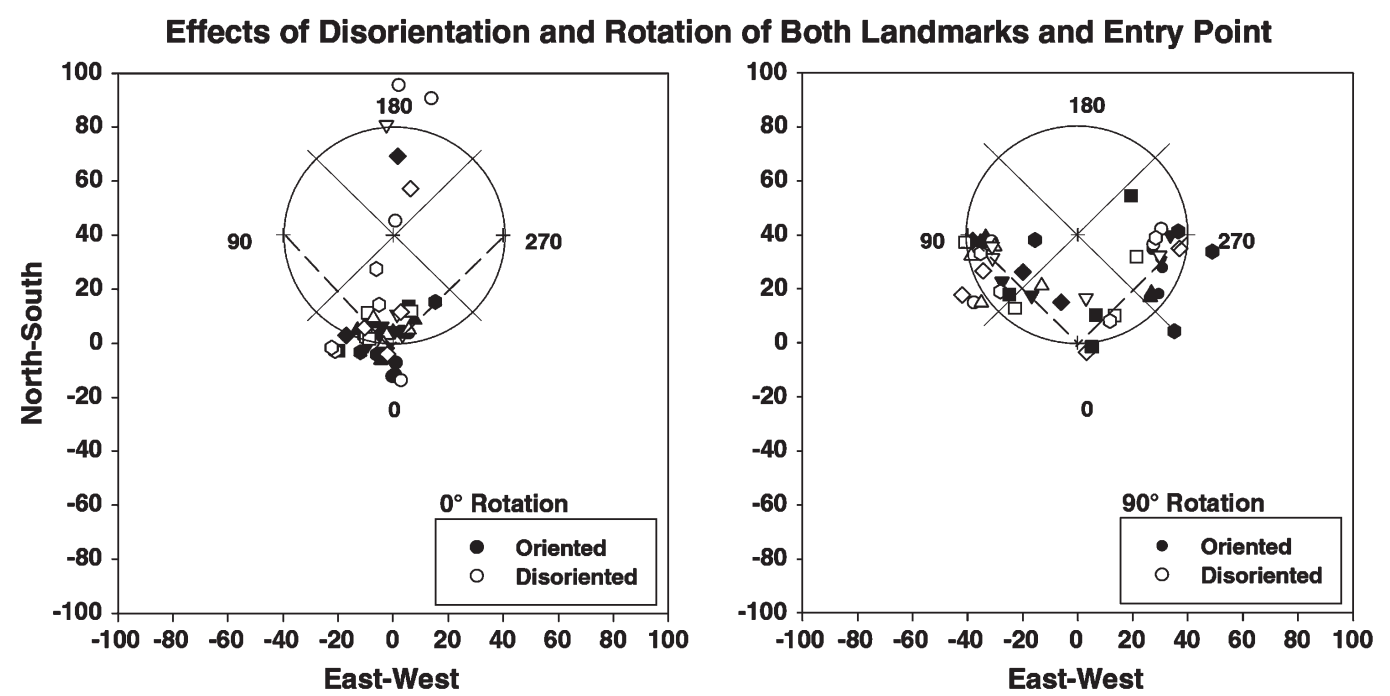

Figure 8. Left panel shows average search location for each bird during the $0^{\circ}$ rotation test when the birds were oriented (filled symbols) and disoriented (open symbols) in Experiment 3. Right panel shows average search location for each bird during the $90^{\circ}$ rotation condition when the birds were oriented (filled symbols) and disoriented (open symbols) in Experiment 3 . The central cross indicates the landmark location and the three crosses on the perimeter of the circle indicate the three possible goal locations. Each symbol shows the search location for each of the four test trials, with each different symbol representing a different bird. The numbers outside of the plot indicate search quadrant (i.e., 0, 90, 180, and 270 quadrants).

ror, $6.9 \mathrm{~cm}$; $0^{\circ}$-direction error, $7.7 \mathrm{~cm} ; 90^{\circ}$-distance error, $6.1 \mathrm{~cm} ; 90^{\circ}$-direction error, $35.3 \mathrm{~cm}$. A Fisher's LSD test showed again that the $90^{\circ}$-direction error significantly exceeded the other three errors, which did not differ among themselves. The rotation manipulation affected the direction of search, but not the distance of search.

The proportion of searches to the goal and rotational quadrants was greater in the $0^{\circ}$ rotation condition compared to the $90^{\circ}$ rotation condition [ANOVA with factors condition $\left(0^{\circ}\right.$ and $90^{\circ}$ rotation) and quadrant (goal and rotational), $M \mathrm{~s}=0.50$ and $0.39 \mathrm{~cm}$, respectively; $F$ $1,5=11.42, p=0.02]$. Overall, searching was primarily concentrated within the goal quadrant compared to the rotational quadrant $(M s=0.66$ and 0.23 , respectively; $F$ $1,5=13.89, p=0.014$ ). The greatest proportion of searching occurred in the goal quadrant during the $0^{\circ}$ condition $(M=0.88)$ which was significantly different from the proportion of searches during all other conditions (Ms $=0.44,0.33$, and 0.13 for, 90 goal quadrant, 90 rotational quadrant, and 0 rotational quadrant; $F_{1,5}=17.86$, $p=0.008)$. Searching was distributed equally between the goal and rotational quadrant during the $90^{\circ}$ rotation condition. As in Experiment 2, if the birds were using only the features within the environment we would not expect a difference between the $0^{\circ}$ and $90^{\circ}$ rotation tests. This clearly was not the case.

As in Experiment 2, if the birds were using an Earthbased cue (e.g., magnetic compass) we would expect to see searches directed to the "absolute compass" goal quadrant (i.e., the 0 quadrant) during the $90^{\circ}$ rotation tests. However, none of the birds made any choices to the rotationally equivalent quadrants during the $0^{\circ}$ ro- tational test sessions, showing that the birds' search was significantly guided by Earth-based cues during the rotational trials $(M=0.23$, proportion of choices to absolute compass goal quadrant during the $90^{\circ}$ rotation tests).

These results suggest that even without access to external environmental cues and inertial information the birds were able to use some source of extra-enclosure information (e.g., magnetic cues) to limit their searching to the three possible goal positions. The results also suggest that the birds' search pattern was not completely controlled by the position of the posters, the wooden beam or the entrance within the enclosure as directional cues. Use of the posters and the entrance would have resulted in a greater shift in responding from the 0 quadrant to only the 90 quadrant, only reliance on the wooden beam would have resulted in rotational ambiguity between the 90 and the 270 quadrants.

The overall pattern of searches seen during the $90^{\circ}$ rotation trials allows us to examine how the birds were using distance and direction information to distribute their searches. The results from Experiments 2 and 3 show that the birds were using multiple cues for determining the direction of the goal location from the landmark, these being the wooden beam, which left a $180^{\circ}$ twofold ambiguity, and some Earth-based cue. These cues were averaged in searching. We can examine the distance from the landmark at which the birds searched in order to determine whether the birds were using a vector-averaging strategy or an independent-averaging strategy, in which distance and direction components of vectors are independently averaged. In Figure 8, vector 


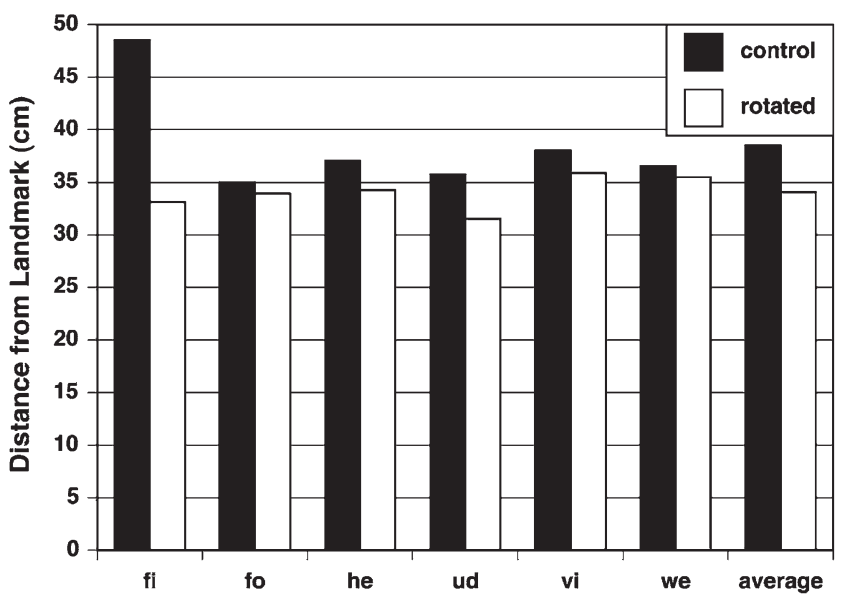

Figure 9. Search distance of individual birds from the landmark in Experiment 3, averaging each bird's performance on all tests. Control $=0^{\circ}$ rotation, rotated $=90^{\circ}$ rotation. The prediction concerning search distances based on the averaging of entire vectors (distance and direction combined) is that the rotated distances should be shorter. The prediction based on the independent averaging of distance and direction components of vectors is that search distances should be equal in the two test conditions. Results favored independent averaging of distance and direction.

averaging means that the birds in the rotated condition should search along the straight line connecting 0 and 90 , or else on the straight line connecting 0 and 270 (thick dashed lines in Figure 8). Search distance from the landmark should be shorter in the rotated condition. According to independent averaging, the search distance from the landmark should be unaffected by the rotation, which affects only the directional component (Cheng 1994, 1998). Search distance from the landmark should be similar in the two conditions. Figure 9 shows that except for one bird, search distances from the landmark are similar in rotated and non-rotated conditions. For the birds as a group, the two conditions did not differ significantly on this variable. These results support the independent averaging of directional and distance components, consistent with what has been found in pigeons (Cheng 1994) and honeybees (Cheng 1998). Independent averaging of directional and distance information suggests some modularity in the computation of the two kinds of information.

\section{Experiment 4}

In Experiment 4, all featural cues were removed during tests. In addition, birds were either disoriented or oriented, and they entered from one of two diametrically opposed entry points. Searches were in general near the virtual target, although substantial scatter was found, and the searches were closer to the landmark than expected (Figure 10). Neither the point of entrance nor disorientation affected the results much. The birds' search error was not influenced by manipulating the entrance or whether or not they were oriented $\left(F_{1.5}=1.85\right.$, $p=0.23 ; F_{1.5}=4.15, p=0.097 ; F_{1,5}=4.13, p=0.098$, main effects of entrance and orientation, and interaction of entrance by orientation, respectively).

As in the previous experiments, we examined potential differences in search accuracy in the distance and direction axes. The birds did not show any overall changes in estimates as a result of where they entered from or whether they were oriented [repeated measures ANOVA with entrance (North-East or South-West), orientation (oriented or disoriented) and error type (distance and direction) as factors, $F_{1,5}=3.64, p=0.11$ and $F_{1,5}=0.56, p=0.49$, for main effect of entrance and orientation, respectively]. As in the previous experiments, the birds showed less error in estimating distance than direction $\left(F_{1,5}=17.71, p=0.008 ; M s=9.6\right.$ and $19.4 \mathrm{~cm}$, respectively). Interestingly, when the birds were oriented their direction estimates were the most accurate $(6.0 \mathrm{~cm}$ of error) and this was significantly better than the other three conditions $\left(F_{1,5}=7.01, p=0.045\right.$, disoriented-direction estimate $=13.15 \mathrm{~cm}$, disoriented-distance estimate $=17.98 \mathrm{~cm}$, and oriented-distance estimate $=20.77 \mathrm{~cm}$ ). Thus, some evidence was found that disorientation affected directional judgments adversely.

As in Experiments 2 and 3, in order to examine, where the birds were directing their searches, we examined the proportion of searches made by each bird in each of the four quadrants. First, we wanted to examine whether the proportion of searches made to the "goal" quadrant (0 quadrant) was different when the birds entered from either the North-East or South-West entrance [ANOVA with factors, entrance (North-East and South-West) and quadrant (goal and rotational)]. The birds' search performance was not influenced by entrance $\left(F_{1,5}=1.00\right.$, $p=0.36)$. Searching was primarily within the goal quadrant compared to the rotational quadrant $\left(F_{1,5}=31.96\right.$, $p=0.002 ; M s=0.50$ and $0.06 \mathrm{~cm}$, respectively). The interaction was not significant $\left(F_{1,5}=2.36, p=0.19\right)$.

\section{Discussion}

Our results show that animals are able to use many forms of visual cues, and perhaps inertial and magnetic cues, to orient within a small-scale environment. These results show that spatial information can be integrated and weighted differentially depending upon the situation. We have shown that the type of training and the shape of the environment may have a strong influence on the ability to encode distance and directional information from landmarks. Using a highly spatially dependent avian model, our study was able to address general questions of multiple cue representation for small-scale navigation. 

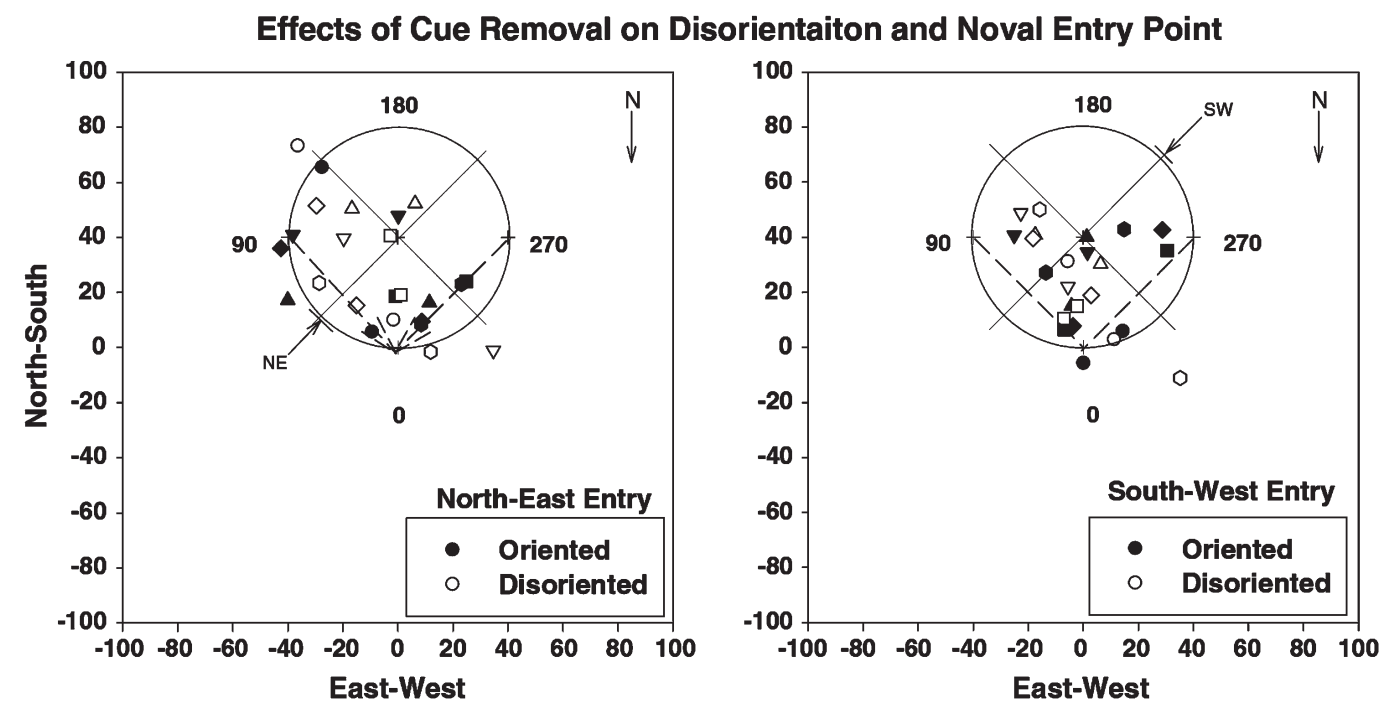

Figure 10. Left panel shows average search location for each bird when the birds entered the experimental enclosure using the North-East entrance and were oriented (filled symbols) or disoriented (open symbols) in Experiment 4 . Right panel shows average search location for each bird when the birds entered the experimental enclosure using the South-West entrance and were oriented (filled symbols) or disoriented (open symbols) in Experiment 4 . The central cross indicates the landmark location and the three crosses on the perimeter of the circle indicate the three possible goal locations. Each symbol shows the search location for each of the four test trials, with each different symbol representing a different bird. The numbers outside of the plot indicate search quadrant (i.e., 0, 90, 180, and 270 quadrants).

In our series of experiments, Clark's nutcrackers had to search for a hidden target located at a constant distance and direction from a single cylindrical landmark. The location of the landmark-goal array varied from trial to trial, such that all cues in the environment could provide directional information but not distance information as to the location of the goal. Experiment 1 showed that errors of localization increased with increasing landmark-goal distance; in fact, performance was poor at landmark-goal distances of 90 and $140 \mathrm{~cm}$. Directional errors were larger than distance errors, when both were measured as centimeters. The rest of the experiments manipulated the directional cues available for localization. These results suggest that two different kinds of cues played a prominent role for the birds. One was the wooden beam: when it was rotated by $90^{\circ}$, the birds tended to rotate their search by $\pm 90^{\circ}$, about equally in the two ambiguous directions. In addition, some form of Earth-based directional cues, perhaps geomagnetic cues, were used to provide directional information (for use of magnetic cues in small-scale navigation see Phillips et al. 2006; Thalau et al. 2007). Other cues played little or no role in directional determination. These included inertial cues, as disorienting the birds had little effect, especially when visual cues were available (in Experiments 2 and 3), and, surprisingly, the posters on the walls. The asymmetrically placed posters could have been used to break the ambiguity posed by the symmetrical wooden beam, but the birds failed to use these cues to do so.

Previous studies (Kamil and Jones 1997, 2000) have reported that error in the estimation of distance increases more rapidly than estimation of direction as distance between a goal and a landmark increases. Our results in Experiment 1 opposed this conclusion, showing that the magnitude of these two types of errors depends on situational factors. We surmise that our circular experimental environment had fewer directional cues than that of rectangular arenas, making directional determination more difficult. In particular, the overall environmental shape or geometry (Cheng 1986) is not informative in a round arena, whereas the rectangular shape used in past studies provides some (albeit ambiguous) directional cues. Environmental geometry is known to be an important cue for many vertebrate animals (Cheng and Newcombe 2005).

The multiple bearings hypothesis (Kamil and Cheng 2001) suggests that multiple sources of bearing information should be used for localization. Experiments 24 show the dominance of two kinds of cues for directional determination in the arena: the wooden beam and some Earth-based cues. That more than one kind of cue is used for directional information supports the hypothesis. But curiously, not all available cues were used. Inertial direction was an unreliable cue and hence played little role in direction. The birds were transported passively and visual cues external to the testing apparatus were at times blocked, making directional determination difficult and less reliable (von Saint Paul 1982). Following principles of optimal Bayesian use of information, an unreliable cue should be weighted little (Cheng et al. 2007; Körding 2007). 
To optimally use multiple cues, Earth-based directional cues should also be used in part when determining direction to a goal, when possible (Cheng et al. 2007; Körding 2007; Körding et al. 2007). We did not manipulate any Earth-based cues, but previous research has established that pigeons are able to determine direction through the use of a magnetic compass (Beason et al. 1997; Wiltschko and Wiltschko 2004). Some suggestive indirect evidence points to the use of infrasound (Hagstrum 2000). Various birds are known to use odors for orientation (pigeons, Wallraff 2004; Gagliardo et al. 2008; procellariiforme birds, Nevitt 2008). Ambient outdoor odor cues, however, were absent in the climatecontrolled indoor setting in which the subject birds were housed and tested (and food-related odors were eliminated through the use of non-reinforced tests), and infrasound cues are likely to be highly attenuated inside a concrete building that is surrounded by the 'infrasound noise' found in an urban setting. Thus, we would guess that the most likely Earth-based cues used by birds in this study and earlier work (Sutton and Shettleworth 2005) are geomagnetic cues. But clearly, this is a topic that requires further empirical evidence.

The lack of reliance on the posters on the walls of the arena is unlikely to stem from their unreliability as a source, given the excellent visual systems that birds possess, and the fact that the birds did use the wooden beam, another visual cue, for directional determination. Cheng et al.'s (2007) Bayesian analysis provides some functional insights in this regard. The key analysis concerns discrepancy among sources of information. When two sources of information are too discrepant, they are highly unlikely to point to the same object. One source should be chosen and the other ignored. Evidence for this strategy in humans can be found (Körding et al. 2007). Cheng et al. (2007) further argue that in the case of sufficient discrepancy, it is individual landmarks, of which posters are exemplars, which should be distrusted. In the natural world, landmarks are numerous, and many of them are similar and thus confusable (e.g., trees). Geomagnetic cues, on the other hand, cannot be confused with another framework or object; the Earth only has one magnetic framework, and in any local area, only one magnetic orientation. No matter how reliable or unreliable this source of information is, it is unmistakable in identity. Thus, individual objects in discrepant directions with respect to an Earth-based frame might be ignored as a source of directional cues.

Cheng et al. (2007) suggested that a large array of landmarks might well be used in preference to directional reference frames used in path integration, since it is highly improbable that an entire array consists of misidentified landmarks. But the wooden beam was just a single, albeit large, object. Perhaps its salience meant that it could not be ignored. It provided some geometric cues, and a salient boundary. Mechanistically, both geometric cues and boundaries are thought to play privileged roles in spatial cognition in mammals (Cheng and Newcombe 2005; Cheng 2008; Doeller and Burgess 2008; Doeller et al. 2008). In humans, measurements with respect to boundaries are not subject to cue competition, whereas measurements with respect to landmarks are (Doeller and Burgess 2008). The situation for our nutcrackers is a hybrid: the boundary provides only directional cues, whereas distance must be measured with respect to a landmark. Nevertheless, the salience of the boundary carved by the wooden beam might have ensured that it was used as directional cues even when it conflicted with Earth-based directional cues.

\section{Acknowledgments}

Research was supported by a grant from National Institute of Mental Health to ACK and a grant from the Natural Sciences and Engineering Research Council of Canada to DMK. We thank Brian Nuest, Tim Suhr, Tamara Griesel, and Jeff Wallace for assistance with conducting the experimental trials. We also wish to thank Walter F. Bischof for assisting with the development of data analyses programs. All experiments reported in this manuscript complied with the current laws of the United States and Canada.

\section{References}

Balda RP (1987) Avian impacts on pinyon-juniper woodlands. In: Everett RL (ed.) Proceedings of the Pinyon-Juniper conference: U.S. Forest Service General Technical Report No. 1NT-215, US Government Printing Office, Washington, DC, pp 525-533

Basil JA (1993) Neuroanatomical and behavioral correlates of spatial memory in Clark's nutcrackers. University of Massachusetts. Unpublished dissertation

Beason RC, Wiltschko R, Wiltschko W (1997) Pigeon homing: effects of magnetic pulses on initial orientation. Auk 114:405-415

Bennett ATD (1993) Spatial memory in a food storing corvid I. Near tall landmarks are primarily used. J Comp Physiol A 173:193-207

Cartwright BA, Collett TS (1983) Landmark learning in bees. J Comp Physiol A 151:521-543

Cheng K (1986) A purely geometric module in the rat's spatial representation. Cognition 23:149-178

Cheng K (1988) Some psychophysics of the pigeon's use of landmarks. J Comp Physiol A 162:815-826

Cheng K (1989) The vector sum model of pigeon landmark use. J Exp Psychol Anim Behav Proc 15:366-375

Cheng K (1994) The determination of direction in landmark-based spatial search in pigeons: a further test of the vector sum model. Anim Learn Behav 22:291-301

Cheng K (1998) Distances and directions are computed separately by honeybees in landmark-based search. Anim Learn Behav 26:455-548

Cheng K (2008) Whither geometry? Troubles of the geometric module. Trends Cogn Sci 12:355-361

Cheng K, Newcombe NS (2005) Is there a geometric module for spatial orientation? Squaring theory and evidence. Psychonom Bull Rev 12:1-23

Cheng K, Narendra A, Wehner R (2006) Behavioral ecology of odometric memories in desert ants: acquisition, retention and integration. Behav Ecol 17:227-235 
Cheng K, Shettleworth SJ, Huttenlocher J, Rieser JJ (2007) Bayesian integration of spatial information. Psychol Bull 133:625-637

Collett TS, Cartwright BA, Smith BA (1986) Landmark learning and visuo-spatial memories in gerbils. J Comp Physiol A 158:835-851

Della Chiesa A, Pecchia T, Tommasi L, Vallortigara G (2006) Multiple landmarks, the encoding of environmental geometry and the spatial logics of a dual brain. Anim Cogn 9:281-293

Doeller CF, Burgess N (2008) Distinct error-correcting and incidental learning of location relative to landmarks and boundaries. Proc Natl Acad Sci USA 105:5909-5914

Doeller CF, King JA, Burgess N (2008) Parallel striatal hippocampal systems for landmarks and boundaries in spatial memory. Proc Natl Acad Sci USA 105:5915-5920

Emlen ST (1970) Celestial rotation-its importance in development of migratory orientation. Science 170:1198-1201

Etienne AS (2003) How does path integration interact with olfaction, vision, and the representation of space? In: Jeffery KJ (ed.) The neurobiology of spatial behavior. Oxford University Press, Oxford, pp 48-66

Etienne AS, Jeffery KJ (2004) Path integration in mammals. Hippocampus 14:180-192

Fiset S (2007) Landmark-based search memory in the domestic dog (Canis familiaris). J Comp Psychol 121:345-353

Gagliardo A, Ioalè P, Savini M, Wild M (2008) Navigational abilities of homing pigeons deprived of olfactory or trigeminally mediated magnetic information when young. J Exp Biol 211:2046-2051

Gallistel CR (1990) The organization of learning. MIT Press, Cambridge

Goodyear AJ, Kamil AC (2004) Clark's nutcrackers (Nucifraga columbiana) and the effects of goal-landmark distance on overshadowing. J Comp Psychol 118:258-264

Gould-Beierle K (2000) A comparison of four corvid species in a working and reference memory task using a radial maze. J Comp Psychol 114:347-356

Hagstrum JT (2000) Infrasound and the avian navigational map. J Exp Biol 203:1103-1111

Healy SA (1998) Spatial representation in animals. Oxford University Press, New York

Jeffery KJ (2003) The neurobiology of spatial behaviour. Oxford University Press, Oxford

Jouventin P, Weimerskirch H (1990) Satellite tracking of wandering albatrosses. Nature 343:746-748

Kamil AC, Balda RP (1985) Cache recovery and spatial memory in Clark's nutcrackers (Nucifraga columbiana). J Exp Psychol Anim Behav Proc 11:95-111

Kamil AC, Cheng K (2001) Way-finding and landmarks: the multiple-bearings hypothesis. J Exp Biol 2043:103-113

Kamil AC, Jones JE (1997) The seed-storing corvid Clark's nutcracker learns geometric relationship among landmarks. Nature 390:276-279

Kamil AC, Jones JE (2000) Geometric rule learning by Clark's nutcrackers (Nucifraga columbiana). J Exp Psychol Anim Behav Proc 26:439-453

Kamil AC, Goodyear AJ, Cheng K (2001) The use of landmarks by Clark's nutcrackers: first tests of a new model. J Navig 54:429-435

Kelly DM, Spetch ML (2001) Pigeons encode relative geometry. J Exp Psychol Anim Behav Proc 27:417-422

Kelly DM, Spetch ML, Heth CD (1998) Pigeons' (Columba livia) encoding of geometric and featural properties of a spatial environment. J Comp Psychol 112:259-269

Körding K (2007) Decision theory: what "should" the nervous system so? Science 318:606-610

Körding K, Beierholm U, Ma JW, Quartz S, Tenenbaum JB, Shams L (2007) Casual inference in multisensory perception. PLOS ONE 2: e943
LaDage LD, Roth TC, Fox RA, Pravosudov VV (2009) Flexible cue use in food-caching birds. Anim Cogn 12:419-426

Lohmann KJ, Lohmann CMF, Endres CS (2008) The sensory ecology of ocean navigation. J Exp Biol 211:1719-1728

Margules J, Gallistel CR (1998) Heading in the rat: determination by environmental shape. Anim Learn Behav 16:404-410

Menzel R, Greggers U, Smith A, Berger S, Brandt R, Brunke S, Bundrock $\mathrm{G}$ et al (2005) Honey bees navigate according to a map-like memory. Proc Natl Acad Sci USA 102:3040-3045

Müller M, Wehner R (1994) The hidden spiral-systematic search and path integration in desert ants, Cataglyphis fortis. J Comp Physiol A 175:525-530

Nevitt GA (2008) Sensory ecology on the high seas: the odor world of the procellariiform seabirds. J Exp Biol 211:1706-1713

Phillips JB, Schmidt-Koenig K, Muheim R (2006) True navigation: sensory bases of gradient maps. In: Brown MF, Cook RG (eds) Animal spatial cognition: comparative, neural, and computational approaches. Online (accessed May 18, 2009): http://www.pigeon. tufts.edu/asc/phillips

Shettleworth SJ (1998) Cognition, evolution and behavior. Oxford University Press, Oxford

Sutton JE, Shettleworth SJ (2005) Internal sense of direction and landmark use in pigeons (Columba livia). J Comp Psychol 119:273-284

Thalau P, Holtkamp-Rötzler E, Fleissner G, Wiltschko W (2007) Homing pigeons (Columba livia $\mathrm{f}$. domestica) can use magnetic cues for locating food. Naturwissenschaften 94:813-819

Tomback DF (1980) How nutcrackers find their seeds. Condor 82:10-19

Towne WF, Moscrip H (2008) The connection between landscapes and the solar ephemeris in honeybees. J Exp Biol 211:3729-3736

Vallortigara G, Zanforlin M, Pasti G (1990) Geometric modules in animals' spatial representations: a test with chicks (Gallus gallus domesticus). J Comp Psychol 104:248-254

Vander Wall SB (1982) An experimental analysis of cache recovery in Clark's nutcrackers. Anim Behav 30:84-94

Vlasak AN (2006) Global and local spatial landmarks: their role during foraging by Columbian ground squirrels (Spermophilus columbianus). Anim Cogn 9:71-80

von Frisch K, Lindauer M (1954) Himmel und Erde in Konkurrenz bei der Orientierung der Bienen. ("Sky and Earth in competition in the orientation of bees.") Naturwissenschaften 41:245-253

von Saint Paul U (1982) Do geese use path integration for walking home? In: Papi FP, Wallraff HG (eds) Avian navigation. SpringerVerlag, Berlin, pp 298-307

Wallraff HG (2004) Avian olfactory navigation: its empirical foundation and conceptual state. Anim Behav 67:189-204

Wehner R (2003) Desert ant navigation: how miniature brains solve complex tasks. J Comp Physiol A 189:579-588

Wehner R, Räber F (1979) Visual spatial memory in desert ants, genus Cataglyphis (Formicidae, Hymenoptera). Experientia 35:1569-1571

Wehner R, Srinivasan MV (2003) Path integration in insects. In: Jeffery KJ (ed.) The neurobiology of spatial behaviour. Oxford University Press, Oxford, pp 9-30

Wiltschko R, Wiltschko W (2004) Clock-shift experiments with homing pigeons: a compromise between solar and magnetic information? Behav Ecol Sociobiol 49:393-400

Wiltschko W, Balda RP, Jahnel M, Wiltschko R (1999) Sun compass orientation in seed-caching corvids: its role in spatial memory. Anim Cogn 2:215-221

Zeil J, Hemmi JM (2006) The visual ecology of fiddler crabs. J Comp Physiol A 192:1-25 